\title{
Analyse de la Révolution Française, suivie du compte rendu de son administration au Ministère de la Guerre
}

Annie Crépin

\section{(2) OpenEdition Journals}

Édition électronique

URL : https://journals.openedition.org/ahrf/2230

DOI : 10.4000/ahrf.2230

ISSN : 1952-403X

Éditeur :

Armand Colin, Société des études robespierristes

\section{Édition imprimée}

Date de publication : 1 septembre 2005

Pagination : 200-202

ISSN : 0003-4436

\section{Référence électronique}

Annie Crépin, «Analyse de la Révolution Française, suivie du compte rendu de son administration au Ministère de la Guerre », Annales historiques de la Révolution française [En ligne], 341 I juillet-septembre 2005, mis en ligne le 27 avril 2006, consulté le 24 avril 2022. URL : http://journals.openedition.org/ ahrf/2230 ; DOl : https://doi.org/10.4000/ahrf.2230

Ce document a été généré automatiquement le 24 avril 2022.

Tous droits réservés 


\section{Analyse de la Révolution Française, suivie du compte rendu de son administration au Ministère de la Guerre}

Annie Crépin

\section{RÉFÉRENCE}

Edmond Louis Alexis Dubois-Crance, Analyse de la Révolution Française, suivie du compte rendu de son administration au Ministère de la Guerre, Clermont-Ferrand, Paléo, coll. « Les Sources de l'histoire de France », 2003, 285 p., ISBN 2-84909-049-2, 33 e.

1 Cet ouvrage qui, outre l'analyse que donne Dubois-Crancé de la Révolution, comporte le compte rendu de son administration au Ministère de la Guerre, contribue à sortir de l'ombre une figure méconnue, sauf des spécialistes de l'histoire militaire pour lesquels il est le précurseur de la conscription et un organisateur de l'armée nouvelle et de l'amalgame, élément fondamental de celle-ci. Il faut saluer cette entreprise méritoire due à B. Ciotti qui fournit une présentation très solide et très actualisée de ces deux textes. Dubois-Crancé ne s'est pas cantonné au domaine militaire et a écrit des ouvrages d'ordre économique et politique dont beaucoup ont disparu pendant la guerre de 1870. Après avoir été démis de ses fonctions par le régime consulaire envers lequel il se montre fort critique, il rédige en 1800 , comme il était tenu de le faire, le compte rendu de son ministériat qui ne fut ni imprimé ni diffusé par son successeur Berthier. Bonaparte le poursuivait de sa vindicte et, bien qu'il se soit cantonné dans une grande réserve jusqu'à sa mort, en 1814, le poursuivra encore dans les Mémoires de SainteHélène. Ainsi, après son départ du Ministère, il est rétrogradé au rang d'adjudantgénéral alors que, depuis 1793, il occupait le grade de général de division et, aucune mesquinerie ne lui étant épargnée, on ergota sur le montant de sa pension! 
2 Dubois-Crancé avait fait une copie de son mémoire, publié en 1885 par les soins du colonel Jung, qui venait d'écrire l'unique biographie du personnage. La même année, toujours à l'initiative de Jung, fut éditée l'analyse de la Révolution française qui ouvre le présent volume et que Dubois-Crancé dit avoir rédigée en l'an X, dans la retraite fort digne où il tenait le rôle de notable des Lumières qu'il avait déjà eu entre 1775 et 1789 , après son départ de l'armée royale.

3 En environ 150 pages, Dubois-Crancé livre sa vision des origines de la Révolution, de ses événements marquants et de ses protagonistes dont il fut, sans d'ailleurs se mettre en valeur ni se justifier, sauf à propos de sa conduite au siège de Lyon. Ces événements marquants sont, ici, politiques beaucoup plus que militaires. On cherchera en vain dans cette œuvre une réflexion sur l'instauration d'une armée nouvelle à laquelle il a pourtant participé. Il est vrai qu'appartenant par son origine à la petite noblesse militaire, comme Guibert et Servan, et ayant été officier jusqu'à l'âge de 25 ans, c'est un praticien, beaucoup moins qu'eux militaire philosophe. S'il a des accents épiques pour évoquer l'élan des volontaires de 1792, il a une vision de Valmy fort éloignée de la légende dorée.

4 Il achève son analyse - puisqu'il ne veut pas s'en tenir à un récit factuel - au moment de l'entrée en vigueur de la Constitution de l'an III et il s'en explique dans un long post scriptum qui lui permet aussi d'évoquer les soubresauts du Directoire jusqu'au coup d'État de Brumaire. «Il suffit d'être convaincu que le peuple n'a pris aucune part aux opérations qui ont suivi l'établissement de la constitution de l'an III, pour regarder notre tâche comme accomplie» (p. 160).

5 Le peuple selon une acception très idéalisée et unanimiste est en effet au centre de cette vision très classique qui privilégie la - et «le» politique - et méconnaît les mouvements des forces sociales ainsi que leurs divergences et ne voit dans leurs revendications que prétexte à manipulations de la part des ennemis de la Révolution. Cette distinction entre le peuple et la populace, qui se livre à des excès condamnables autorisant ses adversaires à discréditer la Révolution, permet à l'auteur de s'inscrire en faux contre la thèse de Burke et celle de l'abbé Barruel qui voient dans la Révolution le résultat d'un complot. Il est en effet un système propre à tous les gouvernements - ici il vise l'Ancien Régime - et aux tenants d'un gouvernement monarchique de vouloir que le peuple ne soit qu'une machine et de toujours supposer un chef qui soit la cause immédiate de tout mouvement populaire, cette résistance - juste et justifiée - étant alors criminalisée sous le nom péjoratif de révolte.

6 Au contraire, Dubois-Crancé s'emploie à montrer la nécessité qui était à l'œuvre au sein de l'action du peuple. C'est le fait que les privilégiés se soient accrochés à leurs privilèges et que la monarchie ait refusé de faire droit au désir légitime de réforme qui a transformé cette aspiration en révolution: en 1789, nul ne songeait à détruire la monarchie et la noblesse eût pu conserver ses titres si elle n'avait pas en même temps voulu conserver ses privilèges. Que l'on recherche les causes de la Révolution dans les querelles du duc d'Orléans avec la Cour ou dans le système de réforme parlementaire voulu par une minorité de la noblesse, tous ces « accessoires » disparaissent devant la grande raison d'État: la volonté du peuple exprimée dans ses cahiers et contrecarrée par la mauvaise foi de la Cour. Dans le discours préliminaire qui précède son analyse, il avait au demeurant affirmé que s'il s'était résolu à faire celle-ci, c'était pour bien persuader ses concitoyens que la Révolution était leur ouvrage et celui de leurs lumières. 
7 Si Dubois-Crancé réfute la théorie du complot comme explication de la conduite du peuple, il ne cesse de dénoncer les intrigues des «aristocrates» qu'il voit partout à l'œuvre, aussi bien dans les épisodes de la Révolution qu'il approuve que dans ceux qu'il rejette ou ne comprend pas : ainsi le 14 Juillet n'est-il que la réplique légitime du peuple à la conjuration ourdie par le comte d'Artois et madame de Polignac « enivrant au cours d'orgies leurs satellites dans les souterrains de Versailles "; de même, le 10 Août a été provoqué par la Cour et n'a été que la riposte des Cordeliers. À l'inverse, Dubois-Crancé fustige les journées d'octobre comme révélatrices des perfidies de la Cour dont les émissaires ont rassemblé tous les gens sans aveu qu'ils pouvaient trouver sous prétexte de venir demander aux États généraux de faire cesser la pénurie des subsistances; il voit dans la journée du 17 juillet la conséquence des manœuvres du gouvernement qui permettent à Louis XVI de promettre d'exécuter une charte contre laquelle il avait protesté d'avance ; la "fameuse » journée du 20 juin est analysée comme le simulacre des grands mouvements révolutionnaires de 1789 , au cours duquel les malveillants de tous les partis réussirent en apparence à rendre complice le peuple de leurs sottises ; les massacres de septembre sont une horrible boucherie que tous - et d'abord les Girondins - laissèrent faire. Quant aux journées de germinal et de prairial, elles sont attribuées à une "tourbe", même si l'auteur reconnaît que le peuple souffrait beaucoup. Il n'est pas jusqu'à l'épisode du camp de Grenelle qu'il qualifie de «bagarre d'ivrognes " poussés par la malveillance.

On l'aura compris, ce sont les journées révolutionnaires qui scandent cette histoire et c'est le peuple, acteur collectif, qui est mis en lumière plus que les acteurs individuels envers lesquels l'auteur se montre critique (l'indigne duc d'Orléans, Marat le fou, les Girondins empêtrés dans leurs médiocres querelles avec ce dernier, Robespierre exalté par l'orgueil et la jalousie) du moins quand ils prétendent jouer un rôle personnel ; il est vrai que Dubois-Crancé règle aussi ses comptes avec ceux qui, avant le 9 Thermidor, l'ont accusé de modérantisme lors du siège de Lyon au cours duquel il était représentant en mission, et ont failli l'envoyer à la mort. Il se montre plus nuancé envers les assemblées et la Société des Jacobins.

9 Les assemblées auxquelles il a participé, la Constituante, même s'il pense qu'elle a duré six mois de trop, la Convention où il représenta les Ardennes, et à laquelle la France doit d'avoir survécu; il juge cette dernière digne de tous les éloges tant qu'elle ne fut que la « démocratie honnête » et avant qu'elle ne devienne « démonomagie » par l'effet du despotisme des comités de salut public et de sûreté générale. Thermidorien de gauche, il juge que le 9 Thermidor sauva la France. Il défend l'action de la Société des Jacobins, dont il fut le premier secrétaire ; non celle de la Terreur, mais cette puissance populaire qui contribua à sauver la France car, en 1789, elle avait eu la sagesse d'associer le peuple à ses travaux; il regrette d'ailleurs que le Directoire se soit délibérément privé de son ressort. En effet, on sent qu'il oppose le bilan glorieux d'une grande époque au Directoire à l'encontre duquel il dresse un constat d'échec qui, selon lui, explique ce 18 Brumaire qu'il condamne tout en exonérant Bonaparte. Pétition de principe, Dubois-Crancé affirme qu'il revient au Premier consul de remédier au " profond malaise moral » qui n'épargne aucune classe de la société après douze ans de bouleversements.

10 À ces pages et à celles qui suivent, le compte rendu où il ne se contente pas de dresser un bilan, mais où il rappelle que, dès avant l'avènement de Bonaparte, « la fortune [des armes] cessa d'être contraire aux républicains » et où il fait des propositions pour 
éviter la dilapidation des fonds publics aux mains des commissaires des guerres, B. Ciotti a ajouté des annexes qui éclairent l'action de Dubois-Crancé, notamment quand il appartint au Comité de Défense de la Convention et qu'il fut à l'origine de la loi du 21 février 1793 qui organisa l'amalgame. 